\title{
SLOWNESS IN SCHIZOPHRENIA
}

\author{
BY \\ ARTHUR HARRIS and MARYSE METCALFE \\ From Bethlem Royal Hospital and the Maudsley Hospital and \\ the Institute of Psychiatry, University of London
}

Slowness is an abnormality which has been regularly and reliably demonstrated by psychometric tests in patients suffering from all forms of mental illness (Shapiro and Nelson, 1955a). In a previous enquiry we found that it was present in some schizophrenic patients and that those with inappropriate affect showed a greater tendency to it than the others (Harris and Metcalfe, 1956).

\section{Nufferno Speed Test}

In this investigation we have used only the Nufferno speed test, which is designed to measure speed as distinct from general level of intelligence. It consists of 19 problems of the Thurstone letterseries type in each of which the patient is presented with series of letters and is required to add at the end of the series the letter which is appropriate to the sequence (Furneaux, 1955, 1956).

Every patient was tested on two versions of equal difficulty. In the first or unstressed version (AA) the patient is allowed to work at his own rate, but in the second or stressed version (AB) the examiner urges him to complete the task as quickly as possible. The score for each version is the mean of the logarithms of the times spent for the completion of the items correctly solved in each version. The higher the score, therefore, the slower the patient.

Several workers have applied this test to schizophrenic subjects and all report a tendency for them to be slower than normals (Nelson, 1953; Ogilvie, 1954; Shapiro and Nelson, 1955a, 1955b; Broadhurst, 1956). The forms of the test used have varied, however, according to the aims in view, so that it is difficult to compare results. For the AA unstressed version the range for an unselected normal population is from 0.6 to 2.1 and for the AB stressed version 0.5 to $1 \cdot 8$. Broadhurst gives the standard deviation for a group of normal adults as 0.32 on the AA version.

\section{Nufferno Test and Affect}

Further examination of the scores of our original group of patients (Harris and Metcalfe, 1956) showed that those of the patients whose affect was markedly inappropriate were grouped closely together in the slower part of the scale, whereas the scores of the patients with moderately inappropriate affect were scattered over a much greater range. Of the original 40 subjects attempting our test battery, one failed to complete the Nufferno tests satisfactorily so had to be discarded for our present purpose.

TABLE I

AFFECT TESTED BY UNSTRESSED VERSION OF NUFFERNO TEST

\begin{tabular}{l|c|c|c}
\hline & $\begin{array}{c}\text { Markedly } \\
\text { Inappropriate } \\
\text { Affect }\end{array}$ & $\begin{array}{c}\text { Moderately } \\
\text { Inappropriate } \\
\text { Affect }\end{array}$ & Normal Affect \\
\hline $\begin{array}{l}\text { Range (mean log } \\
\text { time) }\end{array}$ & $\begin{array}{c}1.054 \text { to } 1 \cdot 390 \\
0 \cdot 10\end{array}$ & $\begin{array}{c}0.698 \text { to } 1.686 \\
0.23\end{array}$ & $\begin{array}{c}0.924 \text { to } 1 \cdot 195 \\
0 \cdot 13\end{array}$ \\
\hline \begin{tabular}{l} 
Standard deviation \\
\hline
\end{tabular}
\end{tabular}

\section{Aims of the Investigation}

Our present aims were to find out whether length of illness or previous physical treatment exerted any influence on speed, whether the degree of slowness in the early part of the illness bore any relationship to the outcome, and whether the slowness varied with the patient's clinical state, i.e., decreased or disappeared when he recovered. For these purposes to the original group of 39 subjects were added 14 more schizophrenic patients from the same hospital, all showing gross psychotic features of a kind which left the diagnosis in no doubt. The ages of this group of 53 patients ranged between 19 and 56 with a mean of 30 . They were tested on a shortened version of the Wechsler-Bellevue test and the mean I.Q. for the group was 107.

\section{Length of Illness}

Twenty-three of our 53 patients had been ill for less than a year, two for over 20 years, and the remaining 28 for intermediate periods. In our previous paper we found no relationship between length of illness and a speed score obtained from the block design test of the Wechsler-Bellevue 
series. However, Table II shows a trend for slowness in the Nufferno speed tests to increase with length of illness before testing.

TABLE II

SLOWNESS RELATED TO LENGTH OF ILLNESS

\begin{tabular}{l|c|c}
\hline \multicolumn{1}{c|}{ Length of Illness } & $\begin{array}{c}\text { Mean } \\
\text { Log-time } \\
\text { AA }\end{array}$ & $\begin{array}{c}\text { Mean } \\
\text { Log-time } \\
\text { AB }\end{array}$ \\
\hline Under 1 year (23 subjects) & 1.107 & 0.970 \\
Between 1 and 2 years (9 subjects) & 1.198 & 0.999 \\
Over 2 years (21 subjects) & 1.211 & 1.065 \\
\hline
\end{tabular}

The AA mean score of the patients with less than one year's illness is different from the mean score of the group with more than two years' illness and is also different from all the rest of the patients at a high level of statistical significance (respectively $\mathbf{P}=0.05$ and between 0.02 and 0.05 ). AB scores are not significantly different. An analysis of variance showed no significant difference.

None of these patients were chronic mental hospital inmates, although some were chronic home invalids, so that stay in an institution cannot have been a factor.

On account of the possibility that this difference was due to the patients who had been ill for a longer period receiving more physical treatment than those whose illness had been shorter, we examined two groups matched for the amount of physical treatment which they had received; all the members of one group had been ill for less than one year and all the members of the other group had been ill for more than two years.

TABLE III

SCORES RELATED TO LENGTH OF ILLNESS (NINE PATIENTS IN EACH GROUP)

\begin{tabular}{l|c|c}
\hline \multicolumn{1}{c|}{ Length of Illness } & AA Mean Log-time & AB Mean Log-time \\
\hline Less than 1 year & 1.132 & 0.985 \\
Over 2 years & 1.241 & 1.030 \\
\hline
\end{tabular}

It will be seen from Table III that the results are consistent with the conclusion that the longer the illness, the slower the score, although the number of subjects is small and the differences are not statistically significant.

TABLE IV

RELATIONSHIP BETWEEN LENGTH OF ILLNESS AND SLOWNESS AND AFFECT (39 SUBJECTS)

\begin{tabular}{|c|c|c|c|c|c|c|}
\hline \multirow[t]{2}{*}{ Length of Illness } & \multicolumn{2}{|c|}{$\begin{array}{c}\text { Markedly } \\
\text { Inappropriate } \\
\text { Affect }\end{array}$} & \multicolumn{2}{|c|}{$\begin{array}{c}\text { Moderately } \\
\text { Inappropriate } \\
\text { Affect }\end{array}$} & \multicolumn{2}{|c|}{$\begin{array}{l}\text { Normal } \\
\text { Affect }\end{array}$} \\
\hline & $\mathbf{A A}$ & $\mathbf{A B}$ & $\mathbf{A A}$ & $\mathbf{A B}$ & $\mathbf{A A}$ & $\mathbf{A B}$ \\
\hline $\begin{array}{l}\text { Under } 1 \text { year } \\
\text { Between } 1 \text { and } 2 \text { years } \\
\text { Over } 2 \text { years }\end{array}$ & $\begin{array}{l}1 \cdot 143 \\
1 \cdot 234 \\
1 \cdot 274\end{array}$ & $\begin{array}{l}0.999 \\
1 \cdot 204 \\
1 \cdot 223\end{array}$ & $\begin{array}{l}1 \cdot 028 \\
1.040 \\
1 \cdot 175\end{array}$ & $\begin{array}{l}0.838 \\
0.858 \\
0.972\end{array}$ & $\begin{array}{l}1 \cdot 104 \\
1 \cdot 221 \\
1 \cdot 146\end{array}$ & $\begin{array}{l}1.042 \\
0.975 \\
0.972\end{array}$ \\
\hline
\end{tabular}

In an attempt to understand this relationship between length of illness and slowness we referred again to the three categories of affective incongruity into which 39 of our subjects had been classified.

Table IV shows that the relationship between length of illness and slowness holds good only for those patients who exhibit inappropriate affect.

\section{Physical Treatment}

Of our 53 subjects, 23 had had no physical treatment at all before testing. Of the remaining 30 , 19 had had insulin coma alone, eight had had electroshock alone, two had had both insulin and E.C.T., two had had barbiturate comas alone, one had had cardiazol convulsions alone, one had had insulin coma and leucotomy, and one had had insulin coma and topectomy. It seemed important to distinguish those who had had physical treatment recently from those who had only had it at a remoter date and this has been done in Table $\mathrm{V}$.

TABLE V

RESULTS IN PATIENTS TREATED PHYSICALLY ACCORDING TO TREATMENT DATE

Physical treatment within past 6 months Physical treatment but not within past

6 months

No physical treatment

It will be seen from Table $V$ that patients whô have received physical treatment tend to be slower but the differences are not statistically significan $\frac{2}{0} \overrightarrow{0}$ Several of those who had no physical treatment had severe illnesses of long duration, so that it is unlikely that this effect is to be explained by the worse or more chronic cases gravitating to the physically treated group. As far as it goes, this finding is in agreement with the results of an investigation into the effects of E.C.T. in states of depression (Shapiro, Campbell, Harris, and Dewsbery, 1958), but not with our own results using the block design speed score (Harris and Metcalfe, 1956), which is of course a very different measure from the Nufferno test.

\section{Outcome of Illness}

As Windle pointed out in his comprehensive review (Windle, 1952), no psychological test has given useful prognostic information in patients suffering from schizophrenic illnesses. Later work $\frac{\text { 의 }}{2}$ by the Columbia-Greystones group has encountered $D$ the difficulty that patients in the acute stage of the illness appear to give the opposite results with the N tests that they use to patients in the chronic stage (Windle and Hamwi, 1953). As one frequently $N$ cannot determine whether a patient is in the acute $\tilde{\omega}$ 
or chronic stage until the outcome of the illness is apparent, these tests are of little practical value. Because of our findings that inappropriate affect, which is itself related to a poor outcome, was accompanied by slower scores on speed tests, we had some grounds for hoping that the Nufferno speed test might prove effective from a predictive point of view.

For this part of the investigation we selected 37 patients out of our group of 54 , rejecting those with chronic illnesses whose condition had remained static for some years and only keeping those for whom the outcome was in doubt. These were interviewed by the psychiatrist (A.H.) a year after they had been tested and assessed according to their clinical and social state. At the time he made the assessment he was ignorant of the test results. During the 12-month follow-up period, of these 37 patients, 23 had insulin coma treatment, four had barbiturate coma treatment, one had E.C.T. and "largactil", and nine had no physical treatment. Of these nine, six had finished a course of insulin coma, one a course of barbiturate treatment, and one a course of cardiazol treatment a week or two before being tested for the first time. There is no evidence that the type of physical treatment given affected the outcome (Ackner, Harris, and Oldham, 1957).

With regard to their clinical state they were divided into three groups, namely, recovered, residual defect, and still psychotic, as defined in a previous paper (Ackner, Harris, and Oldham, 1957).

TABLE VI

CLINICAL OUTCOME IN THREE GROUPS

\begin{tabular}{l|c|c|c}
\hline \multicolumn{1}{c|}{ Clinical Outcome } & AA & AB & $\begin{array}{c}\text { Stress-gain } \\
\text { Score }\end{array}$ \\
\hline Recovered (9 patients) & $1 \cdot 108$ & 0.992 & $0 \cdot 114$ \\
Residual defect (5 patients) & $1 \cdot 137$ & 1.010 & $0 \cdot 127$ \\
Still psychotic (23 patients) & $1 \cdot 177$ & 0.943 & 0.233 \\
\hline
\end{tabular}

There is a trend towards the association of higher speeds on the unstressed version of the test with a more favourable outcome and of high stressgain scores with unfavourable outcome but the difference between the scores of the patients who later recovered and the scores of those who did not does not attain a satisfactory degree of statistical significance and is too small to render it useful in prediction.

With regard to their social state they were also divided into three groups, namely, independent, socially dependent but out of hospital, and in hospital, as defined in the previous paper.

Again high speeds on the unstressed version are associated with a more favourable outcome, but not at a statistically significant level.
TABLE VII

SOCIAL OUTCOME IN THREE GROUPS

\begin{tabular}{l|c|c|c}
\hline \multicolumn{1}{c|}{ Social Outcome } & AA & AB & $\begin{array}{c}\text { Stress-gain } \\
\text { Score }\end{array}$ \\
\hline $\begin{array}{l}\text { Independent (15 patients) } \\
\text { Dependent, ex-hospital }\end{array}$ & 1.122 & 0.990 & 0.132 \\
(12 patients) & 1.165 & 0.990 & 0.166 \\
In hospital (10 patients) & 1.192 & 0.894 & 0.298 \\
\hline
\end{tabular}

The stress-gain score is the difference between the scores on the stressed and unstressed versions. Furneaux (personal communication) suggests that a high stress-gain score represents a lower degree of personal motivation as it indicates that the subject needs more inducement from the examiner to attain his best level of performance. He believes that this score is not related to intellectual achievement and is more related to temperament.

The mean stress-gain score of our group was much higher $(0 \cdot 19)$ than that of a group of university students (0.05) (Furneaux, personal communication). All but two patients were quicker on the stressed than on the unstressed version. The stressgain score differentiates at a satisfactory level of statistical significance between the independent and the "in hospital" groups ( $t$ test, $P$ between 0.02 and 0.05 ). However, when the most appropriate cuttingscore is chosen to discriminate between these two groups three out of 10 of the "in hospital" group and four out of 15 of the independent group are wrongly classified. This overlap, meaning that $28 \%$ of the patients would be wrongly classified, is too great to enable the Nufferno stress-gain score to be used for the prediction of social outcome.

Change in Mental Speed after Clinical Improvement

We tried to find out whether speed increases when the patient improves. This bears on one of the fundamental questions about slowness, whether it is due to a constitutional factor or to impaired function as the result of disease. Six patients were retested one year or more after their initial test and after they had completely recovered. There was a very slight improvement in their score. This slight improvement was also evidenced by a control group of six similar patients who at the time of their second test were still psychotic. These six patients had all just had or were about to have physical treatment at the time of their first test. Because of the complicating effect of the physical treatment which these patients had received no conclusions are possible.

\section{Discussion}

The trends are mainly in the expected directions, although there is an absence of satisfactorily significant figures. Unexpected findings with regard 
to the stress-gain score appear and focus attention on this hitherto neglected measurement. From observation during testing, it seemed that those who showed the higher stress-gain scores reacted more warmly to the examiner than those with the lower scores, who remained more aloof and remote. It may be a matter of motivation, as Furneaux believes, or simply that some degree of aloofness prevents friction between a schizophrenic and his environment and so is a social advantage.

Turning back to the group of 39 patients whose affect has been estimated, those with markedly inappropriate affect show significantly lower stressgain scores than those with moderately inappropriate or normal affect.

TABLE VIII

SIGNIFICANCE OF LOWER STRESS-GAIN SCORES RELATED TO AFFECT

\begin{tabular}{l|c|c|c}
\hline \multirow{2}{*}{$\begin{array}{c}\text { Stress-gain } \\
\text { Score }\end{array}$} & $\begin{array}{c}\text { Markedly } \\
\text { Inappropriate Affect }\end{array}$ & $\begin{array}{c}\text { Moderately } \\
\text { Inappropriate Affect }\end{array}$ & $\begin{array}{c}\text { Normal } \\
\text { Affect }\end{array}$ \\
\cline { 2 - 4 } & 0.070 & 0.147 & 0.148 \\
\hline
\end{tabular}

The $t$ test between the means of the markedly inappropriate affect and other two groups is significant at the 0.01 level.

There is an apparent paradox in that a low stressgain is associated with a good outcome, at least socially, and also with inappropriate affect, which is known to be unfavourable prognostically. Various explanations can be suggested. Social factors are changing rapidly and the community will now accept psychotic patients who a few years ago would have become chronic mental hospital inmates. The success of chlorpromazine in promoting social recoveries indicates that a reduction in tension and volume of affect, which this drug produces, may be socially valuable. The difference between inappropriateness of affect and a diminution of affective response has been emphasized in our previous paper, but it is probable that they are not entirely unconnected. This particular group of patients is a small one and may be atypical in some respects. If we take the 19 patients who of the original 39 were followed up, it will be seen that the relationship between affective state and outcome is

TABLE IX

OUTCOME AFTER ONE YEAR RELATED TO AFFECTIVE STATE

\begin{tabular}{|c|c|c|c|}
\hline \multirow[b]{2}{*}{$\begin{array}{l}\text { Outcome at End of } \\
12 \text { Months }\end{array}$} & \multicolumn{2}{|c|}{ Original Affective State } & \multirow[b]{2}{*}{$\begin{array}{c}\text { Normal } \\
\text { Affect }\end{array}$} \\
\hline & $\begin{array}{c}\text { Markedly } \\
\text { Inappropriate } \\
\text { Affect }\end{array}$ & $\begin{array}{c}\text { Moderately } \\
\text { Inappropriate } \\
\text { Affect }\end{array}$ & \\
\hline $\begin{array}{l}\text { Recovered } \\
\text { Residual defect } \\
\text { Psychotic }\end{array}$ & $\begin{array}{l}\mathbf{1} \\
\mathbf{2} \\
\mathbf{3}\end{array}$ & $\begin{array}{l}1 \\
0 \\
6\end{array}$ & $\begin{array}{l}2 \\
2 \\
4\end{array}$ \\
\hline
\end{tabular}

less clear cut than in the larger previously published series. (The other 20 were too chronically ill to be used for the prognostic study and so were not followed up.)

The criterion of outcome, condition at a fairly arbitrary point in time, which we were obliged to use for practical reasons, is a crude one. These results with the stress-gain scores call for further investigation, especially as they give some hope of information of value in the rehabilitation of patients.

The results with regard to the effect of length of illness fit in well with long-held psychiatric beliefs concerning the type of patient who is likely to deteriorate and the type which is not.

\section{Summary}

The influence of various factors on the mental speed of a group of schizophrenic patients was investigated by means of the Nufferno speed test. Longer duration of illness was associated with slower performance on the unstressed portion of the test, this being more definite in the case of those patients who also showed inappropriate affect. Patients who had had physical treatment tended to be slower on the unstressed portion of the test and those whose illness had a favourable outcome tended to be faster than the others. A significant ${ }_{\alpha}^{\mathbb{D}}$ relationship appeared between low stress-gain score and favourable social outcome. No satisfactory formula for predicting outcome on the basis of this test could be devised. An effort to correlate speed with disease and recovery failed because of the difficulty of finding patients who had gone through their illness without receiving physical treatment, since this latter formed a complicating factor which could not be allowed for.

We are grateful to Mr. W. D. Furneaux for help and advice. This work has been supported by the research fund provided by the Board of Governors of Bethlem Royal Hospital and the Maudsley Hospital to whom we are indebted.

\section{REFERENCES}

Ackner, B., Harris, A., and Oldham, A. J. (1957). Lancet, 1, 607. Broadhurst, A. (1956). Some Variables Affecting Speed of Mental Functioning in Schizophrenics. Ph.D. Thesis, University of London.

Furneaux, W. D. (1955). The Nufferno Tests. Bull. Nat. Found Educ. Res. Engl. Wales No. 6: 32.

- (1956). Manual of Nufferno Speed Tests. London Nat. Found. Educ. Res. Engl. Wales.

Harris, A., and Metcalfe, M. (1956). J. Neurol. Neurosurg. Psychiat., 19,308 .

Nelson, E. H. (1953). Experimental Investigation of Intellectual Speed and Power in Mental Disorders. Ph.D. Thesis, University of London.

Ogilvie, B. C. (1954). A Study of Intellectual Slowness in Schizophrenia. Ph.D. Thesis, University of London.

Shapiro, M. B., Campbell, D., Harris, A., and Dewsbery, J. P. (1958) J. Ment. Sci., 104, 681.

_, and Nelson, E. H. (1955a). Brit. J. med. Psychol., 28, 239.

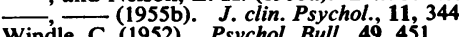

Windle, C. (1952). Psychol. Bull., 49, 451.

-, and Hamwi, V. (1953). J. clin. Psychol., 9, 156. 